\title{
Diagnóstico laboratorial da doença falciforme em neonatos e após o sexto mês de vida
}

\author{
Laboratorial diagnosis of sickle cell disease in the neonate and after the sixth month of life
}

Maria Helena C. Ferraz ${ }^{1}$

Mitiko Murao ${ }^{2}$

\begin{abstract}
A doença falciforme é uma desordem genética da hemoglobina, com alta prevalência no Brasil. Apresenta elevada morbidade e mortalidade, necessitando de identificação e tratamento precoces. O reconhecimento disso tornou o seu diagnóstico obrigatório pelos testes de triagem neonatal, em todo o país. O diagnóstico laboratorial da doença no neonato baseia-se na detecção da hemoglobina $S$ utilizando-se preferencialmente as técnicas de IEF e/ou HPLC que apresentam elevada sensibilidade e especificidade. Estes métodos permitem também a detecção dos portadores de traço e de outras hemoglobinas variantes. Na doença falciforme as principais possibilidades fenotípicas ao nascimento são: $\mathrm{Hb}$ FS, Hb FSC, Hb FSA e Hb FSD-Punjab. Qualquer que seja o fenótipo encontrado para a doença a criança deverá ser encaminhada à consulta médica e o exame repetido após o sexto mês de vida para confirmação do perfil hemoglobínico. Outros exames complementares podem ser necessários para o diagnóstico diferencial das diferentes formas da doença tais como a dosagem de $\mathrm{Hb}_{2}$ e $\mathrm{Hb}$ Fetal como também a realização do estudo familiar. Rev. bras. hematol. hemoter. 2007;29(3):218-222.
\end{abstract}

Palavras-chave: Hemoglobina S; doença falciforme; diagnóstico laboratorial; triagem neonatal.
A doença falciforme decorre de uma alteração de um gene estrutural levando à produção de uma hemoglobina anômala - a hemoglobina S (Hb S). Esta alteração consiste numa mutação no gene da beta globina envolvendo a troca de uma única base nitrogenada - a adenina pela timina - no códon do DNA. Disto resulta a substituição do ácido glutâmico pela valina na posição 6 da cadeia beta com conseqüente modificação físico-química da molécula da hemoglobina.

O termo doença falciforme se aplica a um grupo de desordens genéticas, caracterizado pela presença da hemoglobina S: em homozigose (Hb SS) - também chamada de anemia falciforme; em heterozigose com outras hemoglobinas variantes (Hb SC, Hb SD- ${ }_{\text {Punjab }}$, etc), ou, ainda, em interação com as talassemias ( $\mathrm{Hb} \mathrm{S} / \beta^{0}$ talassemia, $\mathrm{Hb} \mathrm{S} / \beta^{+}$talassemia, $\mathrm{Hb} \mathrm{S} / \alpha$ talassemia). É reconhecidamente uma doença de elevada mortalidade e morbidade, necessitando de identifica- ção e tratamento precoces. ${ }^{1,2}$ No Brasil apresenta alta prevalência e o seu diagnóstico passou a ser obrigatório em todos os estados, pelos testes de triagem neonatal, desde junho de 2001, com a criação do Programa Nacional de Triagem Neonatal (PNTN), juntamente com a triagem do hipotireoidismo congênito, da fenilcetonúria e da fibrose cística. ${ }^{3-5}$ Desta maneira, o Ministério da Saúde deu um importante passo no reconhecimento de sua relevância em saúde pública no Brasil.

A mortalidade na doença falciforme, principalmente por infecção bacteriana ou por seqüestro esplênico, inicia-se após os dois a três primeiros meses de vida, justificando a importância do diagnóstico precoce. A adoção de medidas profiláticas comprovadamente aumenta a sobrevida dos indivíduos afetados e melhora a sua qualidade de vida, apesar de não possibilitar a cura clínica da doença. ${ }^{1,2,5}$

${ }^{1}$ Prof ${ }^{a}$ do Departamento de Propedêutica Complementar da Faculdade de Medicina da UFMG. Supervisora do Laboratório de Triagem Neonatal para Hemoglobinopatias do Núcleo de Ações e Pesquisas em Apoio Diagnóstico (Nupad)/ FM-UFMG.

${ }^{2}$ Fundação Hemominas, Belo Horizonte. Serviço de Hematologia Pediátrica HC-UFMG. 


\section{Diagnóstico laboratorial}

O diagnóstico das hemoglobinopatias é complexo e envolve uma análise que deve considerar, além dos dados clínicos e herança genética, vários fatores como idade da criança por ocasião da coleta, tempo de estocagem e condições de armazenamento da amostra (desnaturação da hemoglobina), entre outras. É conveniente que o laboratório tenha um consultor especializado na área, para auxiliar no esclarecimento dos casos mais complicados.

A tabela 1 mostra as concentrações esperadas para as hemoglobinas no recém-nascido normal e para a criança após o sexto mês de vida (perfil hemoglobínico do adulto). ${ }^{6,7}$

Tabela 1. Concentração normal das hemoglobinas no recém-nascido e adulto

\begin{tabular}{lcc}
\hline Hemoglobina & \% no RN & \% no adulto \\
\hline Hb A $(\alpha 2 \beta 2)$ & 0 a 20 & 96 a 98 \\
Hb A2 $(\alpha 2 \delta 2)$ & 0 a 1 & 2,0 a 3,7 \\
Hb F $(\alpha 2 \gamma 2)$ & 80 a 100 & 0,2 a 1,5 \\
\hline
\end{tabular}

Em recém-nascidos com hemoglobinopatias, principalmente aqueles que envolvem a cadeia beta da globina, os testes de triagem só encontrarão traços da hemoglobina variante, sendo o perfil hemoglobínico característico obtido somente após o sexto mês de vida. Daí a importância da repetição dos exames até o final do primeiro ano de vida. Isto se deve ao fato de que, após os primeiros meses de vida, com o aumento da produção das cadeias beta e com a diminuição correspondente da síntese das cadeias gama, ocorre uma diminuição da concentração da hemoglobina fetal e, no caso de indivíduos normais, um aumento correspondente da concentração da hemoglobina A. Nas hemoglobinopatias, a substituição da hemoglobina $\mathrm{F}$ se faz a partir do código genético herdado. Na doença falciforme a Hb S passa a predominar sobre a Hb F e, assim, emergem as manifestações clínicas.

\section{Diagnóstico laboratorial em neonatos}

O diagnóstico laboratorial da doença falciforme baseiase na detecção da hemoglobina $\mathrm{S}$ e deve seguir as normas estabelecidas no PNTN (Portaria do Ministério da Saúde $n^{\circ}$ 822/01). ${ }^{4}$ Os métodos utilizados identificam, além da doença falciforme, outras hemoglobinopatias, bem como as crianças heterozigotas (portadoras de traço para hemoglobinopatias). ${ }^{7,8}$

O recém-nascido com doença falciforme é, geralmente, assintomático devido ao efeito protetor da hemoglobina fetal, que, neste período da vida, representa cerca de $80 \%$ do total da hemoglobina. Por este motivo, os testes de falcização (pesquisa de drepanócitos) e os testes de solubilidade não se aplicam durante os primeiros meses de vida. Os testes usados em triagem populacional devem ser sensíveis e apresentar boa relação custo-benefício. ${ }^{9}$ Resultados falso-positivos são aceitáveis se todos os casos positivos ou suspeitos forem retestados por outro método. Daí a importância do emprego de duas técnicas diferentes para a determinação do perfil hemoglobínico na primeira amostra da triagem. .,10-13

Inicialmente, os programas de triagem utilizavam dois procedimentos eletroforéticos associados: a eletroforese em acetato de celulose e $\mathrm{pH}$ alcalino seguida da eletroforese em ágar citrato em $\mathrm{pH}$ ácido (Figura 1$).{ }^{7} \mathrm{~A}$ primeira técnica diferencia as hemoglobinas $\mathrm{A}$ da $\mathrm{F}$ e das variantes mais freqüentes, como as hemoglobinas $\mathrm{S}$ e $\mathrm{C}$, mas é incapaz de distinguir as hemoglobinas $\mathrm{A}_{2}$ da $\mathrm{C}, \mathrm{O}$ e E, bem como as hemoglobinas $\mathrm{S}$ da D ou da $\mathrm{G}$ devendo, portanto, ser confirmada pela eletroforese em ágar citrato em $\mathrm{pH}$ ácido. ${ }^{1,2,6-9} \mathrm{~A}$ associação dessas técnicas não constitui o melhor procedimento para triagem neonatal populacional, pois, além de mais trabalhosa para realização em larga escala, apresenta menor sensibilidade e especificidade para o diagnóstico neonatal. ${ }^{9}$

Atualmente, a maioria dos programas de triagem neonatal substituiu os métodos convencionais pela eletroforese por focalização isoelétrica (IEF) (Figura 2) e/ou pela cromatografia líquida de alta resolução (HPLC) (Figura 3). Qualquer uma dessas técnicas pode ser utilizada de forma isolada para a triagem inicial pois constituem métodos de elevada precisão, devendo todo resultado positivo ser repetido em mesma amostra para confirmação. Todos os casos que apresentarem padrão inconclusivo ou duvidoso pela técnica de escolha deverão ser reavaliados por outro método visando aumentar a sensibilidade e a especificidade. Portanto, o ideal é que todo laboratório de triagem trabalhe com os dois métodos, sendo um o de uso rotineiro e o outro para complementação. Nestes casos, as duas técnicas utilizadas deverão ser reportadas no laudo com os resultados.

Para realização desses testes são utilizadas amostras coletadas de sangue fresco de cordão umbilical ou amostras de sangue seco em papel-filtro, coletadas do calcanhar do recém-nascido, seguindo os critérios já estabelecidos para a triagem neonatal das demais doenças triadas na fase I do PNTN. Esses métodos de triagem apresentam excelente sensibilidade e especificidade, podendo, no entanto, estar presentes fatores que interferem com o resultado, tais como prematuridade extrema, transfusão sangüínea anteriormente à coleta de sangue, troca de amostras, erros de identificação ou na digitação de resultados etc. As amostras para os testes de triagem devem ser coletadas sempre antes de qualquer transfusão sangüínea e sempre deve ser questionada a realização de transfusão intra-uterina. Essas informações facilitam a interpretação dos resultados e, diante da ocorrência de transfusão prévia, uma nova amostra deve ser solicitada três meses após a transfusão.

A hemoglobina normal do adulto é denominada hemoglobina A ( Hb A) e a hemoglobina normal do feto é designada hemoglobina fetal (Hb F). Existem mais de 700 hemoglobinas variantes descritas, sendo muitas delas detectadas pelos testes de triagem, especialmente pela IEF. ${ }^{12}$ A maioria 


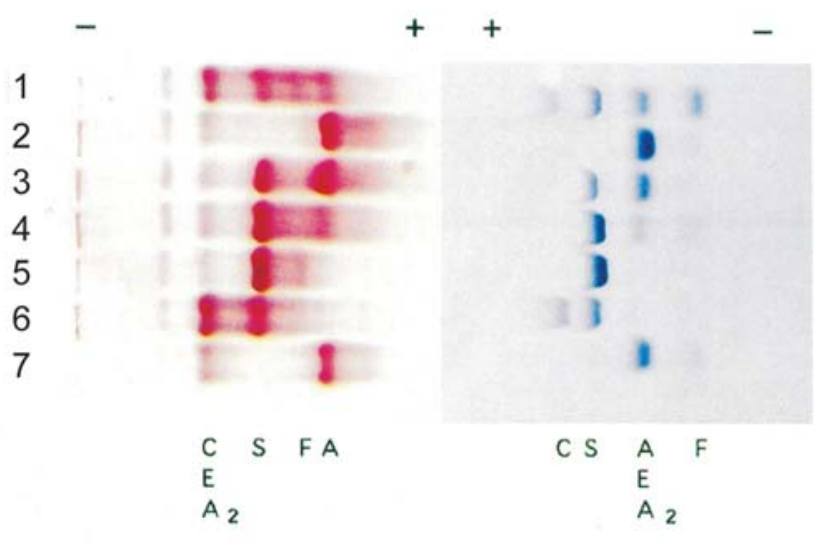

Figura 1. Eletroforese em $\mathrm{pH}$ alcalino (acetato de celulose) e $\mathrm{pH}$ ácido (ágar citrato). Adaptado: Color Plate 2. In: Embury, SH et al (eds.) Sickle Cell Disease, 1th ed. New York: Raven Press, 1994. Legenda: 1. Controles: A, F, S e C;2. Hb AA;3. Hb AS;4. Hb AS; 5. $\mathrm{Hb} \mathrm{SS} ; 6$. $\mathrm{Hb} \mathrm{SC} ; 7$. Hb AE

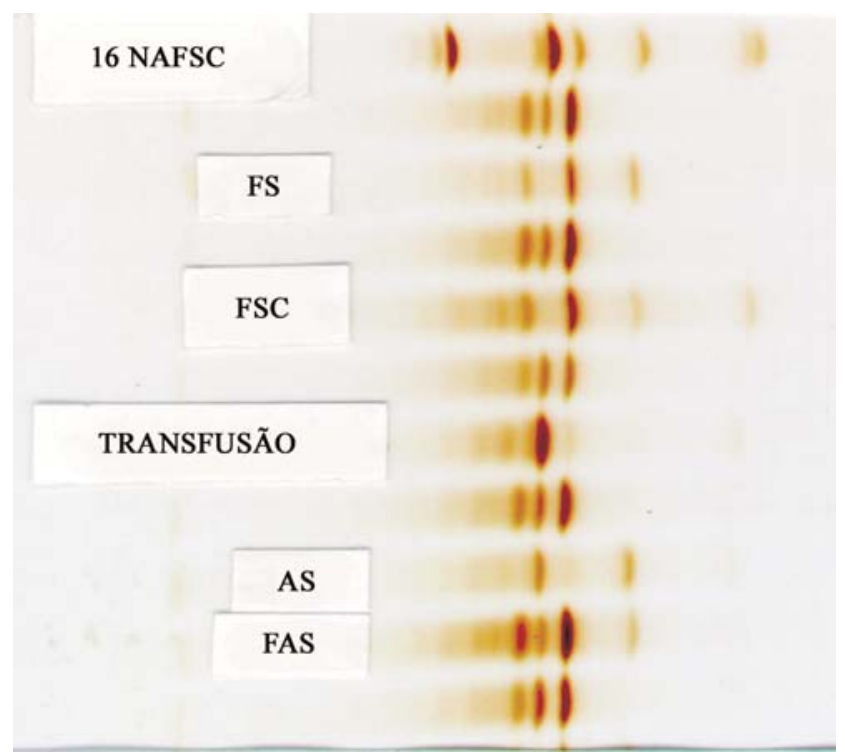

Figura 2. Visão parcial de gel de IEF com várias corridas eletroforéticas. Legenda: NAFSC: controle na posição 16 do gel de IEF Padrões: Hb FS, Hb FSC, Hb AS, Hb FAS; Transfusão: Hb AF em recém-nascido

não apresenta conseqüências clínicas, mas algumas podem determinar anemia ou outros problemas mesmo em heterozigose.

As hemoglobinas identificadas pelos testes são relatadas em ordem crescente de sua concentração. Assim, a representação do perfil hemoglobínico do RN normal é Hb FA, por ser a concentração da hemoglobina fetal ( $\mathrm{Hb}$ F) superior á da hemoglobina normal do adulto (Hb A). Ao nascimento, as crianças com hemoglobinopatias, ou as portadoras de traço, também apresentam predomínio da Hb F. Na doença falciforme teremos as seguintes possibilidades fenotípicas de acordo com a herança genética:

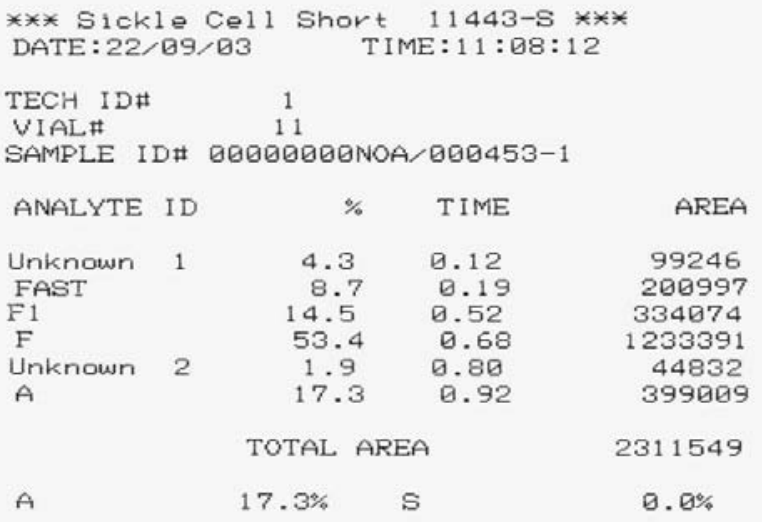

Figura 3. Cromatograma de amostra normal de recém-nascido (HPLC)

- Hb FS (presença de S e ausência de A);

- Hb FSC ou FSD - Punjab, etc (presença de S com outra variante hemoglobínica, na ausência de A);

- Hb FSA (presença de S em maior concentração que A).

Além da hemoglobina S, outras variantes hemoglobínicas podem ser detectadas pelos testes de triagem, sendo as mais comuns as hemoglobinas C, D, E, J e G.

Na doença falciforme, um mesmo resultado da triagem pode estar associado a diferentes genótipos com diversidade clínica. Assim, o fenótipo FS reflete vários genótipos com ampla variação na gravidade das manifestações clínicas. A maioria das crianças FS apresenta a doença falciforme na sua forma homozigótica (anemia falciforme), mas outras situações como a $S / \beta^{0}$ talassemia e a $S / \beta^{+}$talassemia (principalmente em prematuros quando a concentração de $\mathrm{Hb} \mathrm{A}$ ainda pode estar abaixo do limite de detecção do método) e S/PHHF (Persistência Hereditária de Hemoglobina Fetal) também podem apresentar esse achado nos testes de triagem. Pode ocorrer, também, co-herança com a $\alpha$-talassemia.

Qualquer que seja o fenótipo encontrado, todo recémnascido com resultado positivo para a doença falciforme requer encaminhamento médico, e uma nova amostra confir- 
Tabela 2. Resultados dos Testes de Triagem Neonatal para Doença Falciforme

\begin{tabular}{|c|c|c|}
\hline FS & $\begin{array}{c}\text { Anemia } \\
\text { Falciforme SS }\end{array}$ & $\begin{array}{l}\text { Hemólise e anemia } \\
\text { moderada a grave } \\
6-12 \text { meses }\end{array}$ \\
\hline FS & $\mathrm{S} / ß^{0}$ talassemia & $\begin{array}{l}\text { Hemólise e anemia } \\
\text { moderada a grave } \\
6-12 \text { meses }\end{array}$ \\
\hline FS & S/PHHF & $\begin{array}{c}\text { Ausência de hemólise ou } \\
\text { anemia }\end{array}$ \\
\hline $\begin{array}{l}\text { FSA ou FS } \\
\text { (se A abaixo } \\
\text { do limite de } \\
\text { detecção } \\
\text { do método) }\end{array}$ & $\mathrm{S} / \mathrm{B}^{+}$talassemia & $\begin{array}{l}\text { Anemia discreta } \\
2 \text { anos }\end{array}$ \\
\hline FSC & $\begin{array}{l}\text { Hemoglobinopatia } \\
\text { SC }\end{array}$ & $\begin{array}{l}\text { Anemia discreta ou } \\
\text { ausente } 2 \text { anos }\end{array}$ \\
\hline FSD-Punjab & $\begin{array}{l}\text { Hemoglobinopatia } \\
\text { SD }\end{array}$ & $\begin{array}{l}\text { Anemia discreta a } \\
\text { moderada } 2 \text { anos }\end{array}$ \\
\hline
\end{tabular}

matória deve ser analisada após o sexto mês de vida. Um protocolo de acompanhamento incluindo medidas profiláticas e educativas deve ser então instituído.

Os testes de falcização (pesquisa de drepanócitos) e de solubilidade são inadequados para o recém-nascido por levarem a resultados falsos-negativos devido aos altos níveis de hemoglobina fetal e aos baixos níveis da hemoglobina $S$ presentes nesta ocasião. Outros exames como hemograma, reticulócitos, estudo familiar (estudo do sangue dos pais) são úteis na diferenciação diagnóstica. Em alguns casos é necessária a utilização de técnicas de biologia molecular. Convém lembrar que o exame do sangue dos pais poderá gerar situações de exclusão de paternidade e, muito raramente, até de maternidade. Por isso, deve ser solicitado somente após esclarecimento deste fato à mãe e, preferencialmente, com termo de consentimento assinado.

$\mathrm{O}$ encontro exclusivo de $\mathrm{Hb} \mathrm{F}$ no exame de triagem pode ocorrer em crianças normais cuja hemoglobina A ainda não se manifestou devido à prematuridade, bem como em crianças com beta talassemia major ou outra forma de talassemia. Nesses casos, afastada a prematuridade, deve ser realizado o encaminhamento médico. Os métodos de triagem não permitem a detecção de crianças com beta talassemia minor ou intermédia.

A hemoglobinopatia C homozigótica (Hb FC) ou em interação com a beta talassemia (Hb FCA) pode ser seguramente identificada na triagem neonatal tanto pela IEF quanto pelo HPLC. Quanto às hemoglobinas D, o método de IEF apresenta maior especificidade para os diferentes tipos de $\mathrm{Hb}$ D, sendo o HPLC mais limitado nessa identificação, permitindo uma separação cromatográfica segura apenas da $\mathrm{Hb}$ D-Punjab. Nesses casos é muito importante a associação de ambos os métodos..$^{10} \mathrm{~A}$ hemoglobina $\mathrm{E}$ é pouco freqüente no nosso meio e o método de IEF permite uma identificação mais segura que o HPLC. ${ }^{10}$
Apesar de ambos os métodos poderem detectar a hemoglobina Bart's $\left(\gamma_{4}\right)$, um estudo comparativo utilizando técnicas moleculares ainda não foi realizado para uma padronização segura do diagnóstico das $\alpha$-talassemias. Até que isto ocorra, os casos com elevadas concentrações de Hb Bart's e compatíveis com formas graves de $\alpha$-talassemia, como a doença da hemoglobina $H$, devem ser relatadas e encaminhadas para consulta médica.

Resultados para os portadores de traço para as hemoglobinas S (Hb FAS) e C (Hb FAC) podem ser liberados por qualquer um dos métodos. Para os portadores de traço para as hemoglobinas D (Hb FAD), E (Hb FAE) ou outra variante desconhecida (Hb FAV), os resultados devem ser liberados após confirmação por ambos os métodos (IEF e HPLC), necessitando algumas vezes um estudo do sangue dos pais e encaminhamento médico, bem como o uso de técnicas de biologia molecular quando disponíveis.

\section{Diagnóstico laboratorial após o $6^{\circ}$ mês de vida}

Como já abordado, os recém-nascidos diagnosticados à triagem neonatal como prováveis doentes falciformes devem ser reavaliados laboratorialmente após o $6^{\circ}$ mês de vida, e o estudo familiar deve complementar esta avaliação. Um teste simples como a pesquisa de drepanócitos, embora incapaz de diferenciar os vários genótipos, pode confirmar a presença da $\mathrm{Hb} \mathrm{S}$. A repetição da eletroforese confirma o perfil hemoglobínico num melhor momento, ocasião em que se aproxima do perfil do adulto. Nas interações com $S / \beta^{0}$ talassemia e $S / \beta^{+}$talassemia, a quantificação das hemoglobinas $\mathrm{A}_{2}$ e fetal é fundamental para o diagnóstico diferencial com a anemia falciforme, juntamente com a clínica e o estudo familiar. Desta forma podemos considerar que, para os pacientes que não foram submetidos à triagem neonatal e para diagnóstico diferencial entre as diferentes formas de doença falciforme, além dos sinais e sintomas clínicos, os seguintes exames podem ser utilizados:

- Eletroforese em pH alcalino em acetato de celulose;

- Eletroforese em pH ácido em ágar citrato ou gel de agarose;

- IEF:

- HPLC (kit beta tal);

- Pesquisa de drepanócitos e/ou teste de solubilidade;

- Dosagem da hemoglobina fetal pela técnica de desnaturação alcalina ou por HPLC (kit beta tal);

- Dosagem de hemoglobina $A_{2}$ por microcromatografia em coluna ou por HPLC (kit beta tal);

- Hemograma completo (hematoscopia, VCM) e reticulócitos;

- Estudo do sangue dos pais (estudo familiar).

A tabela 3 apresenta as principais características laboratoriais de diferentes tipos de doença falciforme e do traço falciforme após o $6^{\circ}$ mês de vida. 
Tabela 3. Achados hematológicos nas hemoglobinopatias após o $6^{\circ}$ mês de vida

\begin{tabular}{|c|c|c|c|c|c|c|}
\hline Diagnóstico & $\begin{array}{l}\text { Gravidade } \\
\text { clínica }\end{array}$ & $\begin{array}{c}\mathrm{Hb}(\mathrm{g} / \mathrm{dl}) \\
\text { média (variação) }\end{array}$ & $\begin{array}{c}\text { VCM (fl) } \\
\text { média (variação) }\end{array}$ & $\begin{array}{l}\text { Reticulócito (\%) } \\
\text { média (variação) }\end{array}$ & $\begin{array}{l}\text { Morfologia } \\
\text { eritrocitária }\end{array}$ & $\begin{array}{c}\text { Eletroforese } \\
\mathrm{Hb}(\%)\end{array}$ \\
\hline SS & $\begin{array}{l}\text { Moderada } \\
\text { a grave }\end{array}$ & $\begin{array}{c}7,5 \\
(6,0-9,0)\end{array}$ & $\begin{array}{c}93 \\
(80-100)\end{array}$ & $\begin{array}{c}11,0 \\
(4,0-30,0)\end{array}$ & $\begin{array}{c}\text { Drepanócitos }(+++) \\
\text { Alvo }(+) \\
\text { Eritroblastos }(++)\end{array}$ & $\begin{array}{c}\text { S: } 80-90 \\
\text { F: } 2-15 \\
\text { A2: }<3,5\end{array}$ \\
\hline SC & $\begin{array}{l}\text { Leve a } \\
\text { moderada }\end{array}$ & $\begin{array}{c}11,0 \\
(9,0-14,0)\end{array}$ & $\begin{array}{c}80 \\
(75-90)\end{array}$ & $\begin{array}{c}3,0 \\
(1,0-6,0)\end{array}$ & $\begin{array}{l}\text { Drepanócitos }(+) \\
\quad \text { Alvo }(++)\end{array}$ & $\begin{array}{l}\text { S: } 45-55 \\
\text { C: } 45-55 \\
\text { F: } 0,2-7\end{array}$ \\
\hline $\mathrm{S} / \beta^{+}$tal & $\begin{array}{l}\text { Leve a } \\
\text { moderada }\end{array}$ & $\begin{array}{c}11,0 \\
(8,0-13,0)\end{array}$ & $\begin{array}{c}73 \\
(65-78)\end{array}$ & $\begin{array}{c}3,0 \\
(1,0-6,0)\end{array}$ & $\begin{array}{c}\text { Hipocromia }(++) \\
\text { Microcitose }(+) \\
\text { Drepanócitos }(0 /+) \\
\text { Alvo }(++)\end{array}$ & $\begin{array}{l}\text { S: } 55-75 \\
\text { A: } 15-30 \\
F: 1-20 \\
\text { A2 }>3,5\end{array}$ \\
\hline$S / \beta^{0}$ tal & $\begin{array}{l}\text { Moderada } \\
\text { a grave }\end{array}$ & $\begin{array}{c}8,0 \\
(7,0-10,0)\end{array}$ & $\begin{array}{c}69 \\
(64-74)\end{array}$ & $\begin{array}{c}8,0 \\
(3,0-18,0)\end{array}$ & $\begin{array}{c}\text { Hipocromia }(+++) \\
\text { Microcitose }(++) \\
\text { Drepanócitos }(0 /+) \\
\text { Alvo }(++)\end{array}$ & $\begin{array}{l}S: 60-85 \\
F: 13-35 \\
A 2>3,5\end{array}$ \\
\hline AS & Assintomático & Normal & Normal & Normal & Normal & $\begin{array}{c}\text { A: } 55-60 \\
\text { S: } 38-45 \\
\text { A2 até } 3,5\end{array}$ \\
\hline
\end{tabular}

\section{Abstract}

Sickle Cell disease (SCD) is a genetic disorder of the hemoglobin, with high prevalence in Brazil. It presents high morbidity and mortality with early identification and treatment being necessary. The recognition of this situation has made the diagnosis of SCD mandatory through neonatal screening in Brazil. SCD Laboratorial diagnosis in the neonate is based on the detection of S hemoglobin, in preference, using IEF and/or HPLC techniques, which present high sensitivity and specificity. These methods also allow the detection of carriers traits and other variant hemoglobins. The main phenotypic possibilities on SCD at birth are: $\mathrm{Hb}$ FS, $\mathrm{Hb}$ FSC, $\mathrm{Hb}$ FSA and Hb FSD-Punjab. The child should be referred for medical assessment independent of the phenotype found and the examination being repeated after six months of life to confirm of the hemoglobinic profile. Other complementary examinations may be necessary for differential diagnoses of the different forms of the disease, such as the measurement of $\mathrm{Hb} \mathrm{A}_{2}$ and Fetal $\mathrm{Hb}$, as well as a study of the family history. Rev. bras. hematol. hemoter. 2007;29(3):218-222.

Key words: Hemoglobin S; sickle cell disease; diagnosis; neonatal screening.

\section{Referências Bibliográficas}

1. National Institute of Health. The Management of Sickle Cell Disease. NIH Publication, 2002.

2. Ministério da Saúde: Manual de Diagnóstico e Tratamento de Doenças Falciformes. Brasília: Anvisa, 2001.

3. Zago MA, Costa FF. Hereditary hemoglobin disorders in Brazil. Trans R Soc Med Hyg. 1983;79:385-8.

4. Ramalho AS, Magna LA, Paiva-e-Silva RB. A portaria $n^{\circ} 822 / 01$ do Ministério da Saúde e as peculiaridades das hemoglobinopatias em saúde pública no Brasil. Cad Saúde Pública. 2003;19:1195-9.
5. Serjeant GR. Screening for sickle cell disease in Brazil. Lancet 2000;356:168-9.

6. Serjeant GR. Sickle Cell Disease. Oxford, Oxford University Press, 2nd Ed., 1992.

7. Embury SH et al (eds.). Sickle Cell Disease: Basic Principles and Clinical Practice, $1^{\text {th }}$ ed. New York: Raven Press, 1994, p.902.

8. Naoum PC. Diagnóstico das Hemoglobinopatias. São Paulo, Sarvier. Ed. Livros Médicos, p. 12-17, 1987.

9. Sickle Cell Disease Guideline Panel. Sickle Cell Disease: Screening, diagnosis, management, and counseling in newborns and infants. Clinical Practice Guideline № 6. AHCRP Pub. No 93-0562. Rockville, MD: Agency for Health Care Policy and Research, Public Health Service, U.S. Department of Health and Human Services. April 1993.

10. Campbell M, Henthron JS, Davies SC. Evaluation of cation exhange HPLC compared with isoeletric focusing for neonatal hemoglobinopathy screening. Clinical Chemistry. 1999;45(7); 969-75.

11. Eastman JW, Wong R, Liao CL, Morales DR. Automated HPLC screening of newborns for sickle cell anemia and other hemoglobinopathies. Clin Chem. 1996;42:(5)704-10.

12. Huisman THJ. The separation and identification of hemoglobin variants by isoelectric focusing electrophoresis: An interpretive Guide. Isolab, 1997.

13. Lorey F, Cunningham G, Shafer F, Lubin B, Vichinsky E. Universal screening for hemoglobinopathies using high performance liquid chromatography: clinical results of 2.2 million screens. Eur J Hum Cenet. 1994;2:262-71.

O tema apresentado e o convite aos autores constam da pauta elaborada pelo co-editor, prof. Rodolfo Delfini Cançado.

Avaliação: Co-editor e um revisor externo.

Publicado após revisão e concordância do editor.

Conflito de interesse: não declarado.

Recebido: 26/06/2007

Aceito: 13/08/2007 